\title{
Ovarian granulomas: a report of 32 cases
}

\author{
W G McCluggage, D C Allen
}

\begin{abstract}
Aims-To determine the causes of ovarian granulomatous inflammation and to discuss the differential diagnoses.

Methods-The pathological features of all ovarian granulomas identified by pathology SNOMED coding in Northern Ireland over a 13 year period were reviewed. Case notes of patients were also reviewed.

Results-The most common cause of ovarian granuloma was a foreign body reaction to suture material introduced at a previous operative procedure (15 cases). Other causes were Crohn's disease (four cases), previous diathermy (two cases), tuberculosis (two cases), a necrotising reaction following previous surgery (two cases), endometriosis (one case), and bacterial tubo-ovarian abscess (one case). In five cases, no cause was apparent for the granulomatous inflammation. In these, varying numbers of small, well circumscribed cortical granulomas were present. These cases correspond to so-called "idiopathic" cortical granulomas.

Conclusion-The study confirms the wide range of conditions which can give rise to ovarian granulomatous inflammation.

(F Clin Pathol 1997;50:324-327)
\end{abstract}

Keywords: ovary; granulomatous inflammation; differential diagnosis

The finding of ovarian granulomas in a surgical pathology specimen is relatively uncommon. Worldwide, the most common cause of ovarian granulomatous inflammation is tuberculosis, usually in association with tuberculous salpingitis. In developed countries, descriptions of ovarian granulomas are usually reports of single or small numbers of cases. We describe 32 cases of ovarian granulomas collected from all the pathology departments in Northern Ireland over a 13 year period. The case notes of all patients were reviewed. We describe the clinicopathological features and discuss the differential diagnoses of ovarian granulomas.

\section{Department of} Pathology, Belfast City

Hospital Trust, Belfast, Northern Ireland

D C Allen

Correspondence to: Dr WG McCluggage, Department of Pathology, Royal Group of Hospitals Trust, Grosvenor Road, Belfast BT12 6BL Northern Ireland.

Accepted for publication 16 January 1997 were identified from the records of the pathology departments of these hospitals over the 13
Table 1 Causes of ovarian granulomas in 32 patients

\begin{tabular}{ll}
\hline Cause & Number of cases \\
\hline Foreign body reaction to & \\
$\quad$ suture & 15 \\
Crohn's disease & 4 \\
Previous diathermy & 2 \\
Tuberculosis & 2 \\
Postoperative necrotising & \\
$\quad$ reaction & 2 \\
Endometriosis & 1 \\
Tubo-ovarian abscess & 1 \\
Idiopathic & 5
\end{tabular}

Table 2 Clinical details and pathological features of five patients with idiopathic ovarian granuloma

\begin{tabular}{lll}
\hline Age (years) & $\begin{array}{l}\text { Menopausal } \\
\text { status }\end{array}$ & Associated pathology \\
\hline 45 & Perimenopausal & $\begin{array}{l}\text { Adenomyosis, Brenner } \\
\text { tumour, paratubal cyst }\end{array}$ \\
43 & Premenopausal & $\begin{array}{l}\text { Uterine fibroids } \\
\text { Pystic hyperplasia } \\
\text { endometrium, endometriosis, } \\
\text { (uterine fibroids }\end{array}$ \\
64 & Postmenopausal & $\begin{array}{l}\text { Endometrial adenocarcinoma } \\
\text { Uterine fibroids }\end{array}$ \\
\hline
\end{tabular}

year period 1984-96. Haematoxylin and eosin stained sections of all cases were reviewed and the case notes of all patients were examined.

Cases of granulomatous reaction to keratin in ovarian teratomas and cases of histiocytic reactions in endometriosis were excluded.

\section{Results}

Over the period of the study, 32 cases of ovarian granulomas were identified. Table 1 shows the causes of ovarian granulomas determined from the pathological features and case notes. Table 2 provides brief clinical details and associated pathological findings in the five cases of idiopathic granulomas, all of which were incidental findings in ovaries removed during hysterectomy.

\section{POSTOPERATIVE CASES}

The most common cause of ovarian granulomas (15 cases) was a foreign body reaction to suture material, introduced at a previous operative procedure. All cases contained foreign body giant cells in relation to doubly refractile suture material (fig 1). In two additional cases, areas of fibrinoid necrosis were surrounded by a palisaded histiocytic reaction which included several Langhans-type giant cells (fig 2). Organisms were not identified with special stains. There was a history of previous surgery in both cases and these were presumed to be unusual postoperative reactions.

\section{CROHN'S DISEASE}

Three of the four cases in Crohn's disease patients had similar features; two of these 


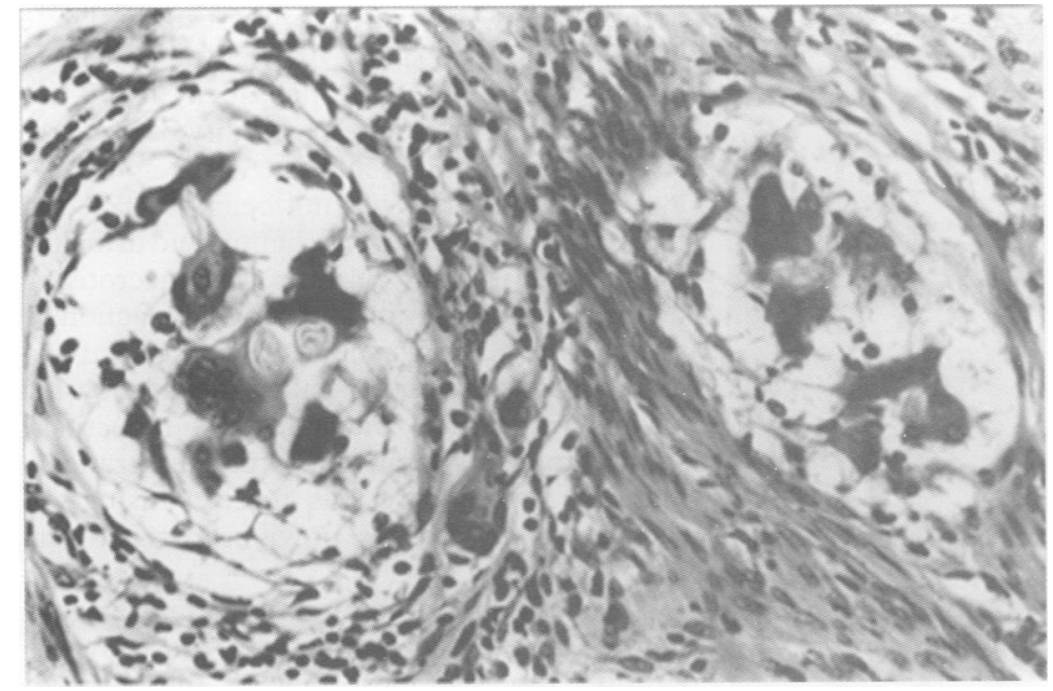

Figure 1 Granuloma containing foreign body type giant cells.

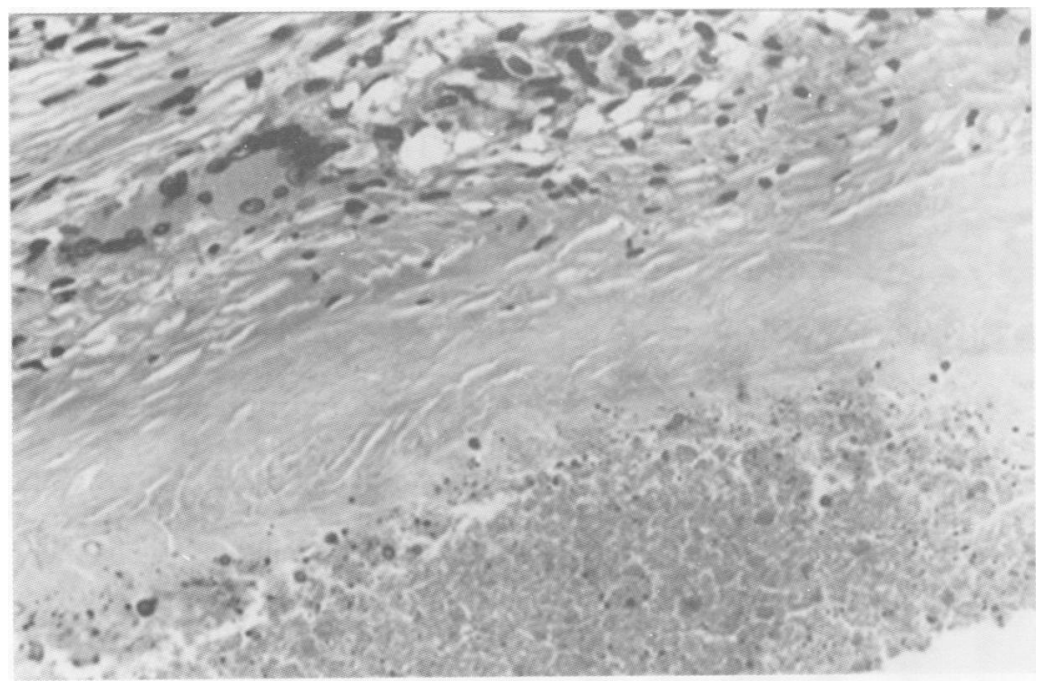

Figure 2 Granuloma containing central area of fibrinoid necrosis with surrounding histiocytic reaction, including an occasional giant cell.

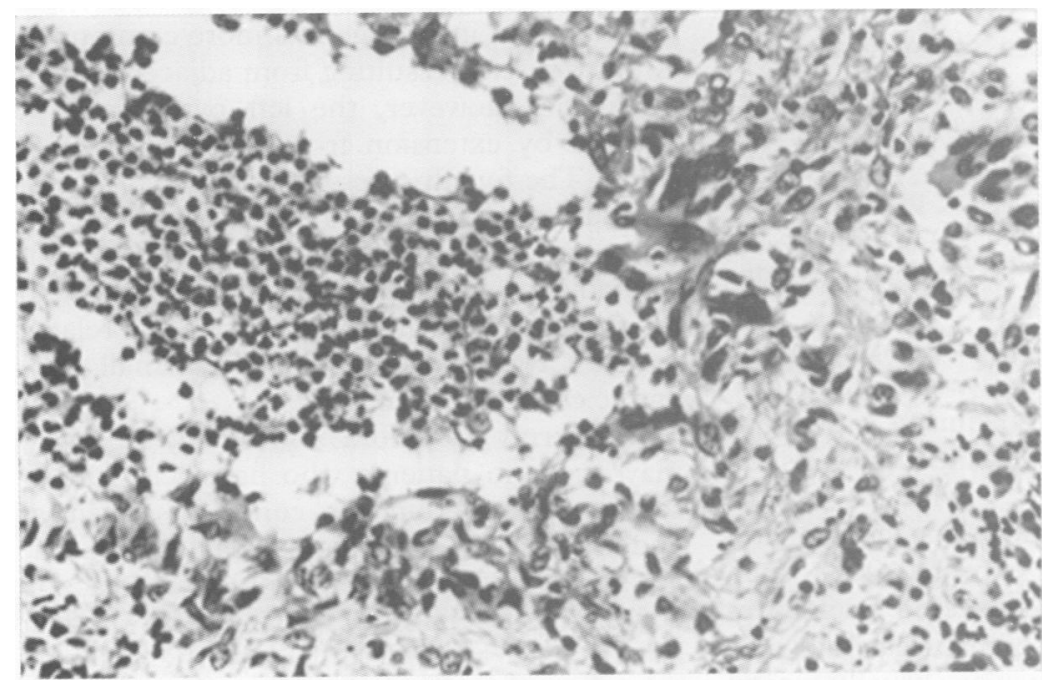

Figure 3 Granuloma in a Crohn's disease patient showing a central area of suppuration and surrounding giant cells. of the granulomas had central suppuration with microabscess formation (fig 3). Fissure ulcers, lined by inflammatory granulation tissue, extended from the ovarian surface deep into the parenchyma, and fragments of vegetable material were identified. In the fourth case, which involved the left ovary, several small, well circumscribed, non-necrotising granulomas were present in the ovarian cortex.

PREVIOUS DIATHERMY

Two cases of florid granulomatous reaction to previous ovarian diathermy were identified. In these cases, areas of coagulated tissue were surrounded by a histiocytic and giant cell reaction (fig 4).

\section{TUBERCULOSIS}

The two cases of tuberculosis exhibited bilateral involvement of ovaries and fallopian tubes. Numerous granulomas with central caseous necrosis and containing Langhans-type giant cells were present. In one case, granulomas were also identified within the endometrium and in the other case there was peritoneal involvement. Special stains revealed acid fast bacilli in one case and in the other there was culture proven mycobacterium tuberculosis.

\section{IDIOPATHIC CASES}

In five cases, no cause for the ovarian granoluma could be determined. The left ovary was affected in three cases and the right ovary in two. All exhibited similar histological features. Granulomas were confined to the ovarian cortex and were generally few in number, varying from one to several. They were small, well circumscribed, and composed of lymphocytes, histiocytes, and multinucleate giant cells, without central necrosis (fig 5). In several cases, small collections of lymphocytes were present in the ovarian cortex, separate from the granulomas. Organisms were not identified with special stains.

\section{OTHER CASES}

In one case, well circumscribed granulomas were present in an ovary with coexistent endometriosis. In another case, occasional well circumscribed granulomas were present in a tubo-ovarian abscess. No acid fast bacilli or other organisms were identified with special stains. However, culture revealed a mixed bacterial growth.

\section{Discussion}

In developed countries, the female genital tract in general and the ovaries in particular are rarely the site of granulomatous inflammation and it is relatively uncommon to encounter ovarian granulomas in a surgical pathology specimen. Worldwide, the most common cause of ovarian granulomatous inflammation is tuberculosis. Both ovary and adjacent fallopian tube are usually affected and there is generally involvement of other parts of the female genital tract, especially the endometrium. We identified two cases of ovarian involvement in tuberculosis in the present study. Other infectious agents which may result in ovarian granulomas involved the right ovary. Num granulomas were present throughout the ovarian parenchyma. The granulomas were composed of epithelioid histiocytes, lymphocytes, plasma cells, and multinucleate giant cells, some of which were of foreign body type. Many 


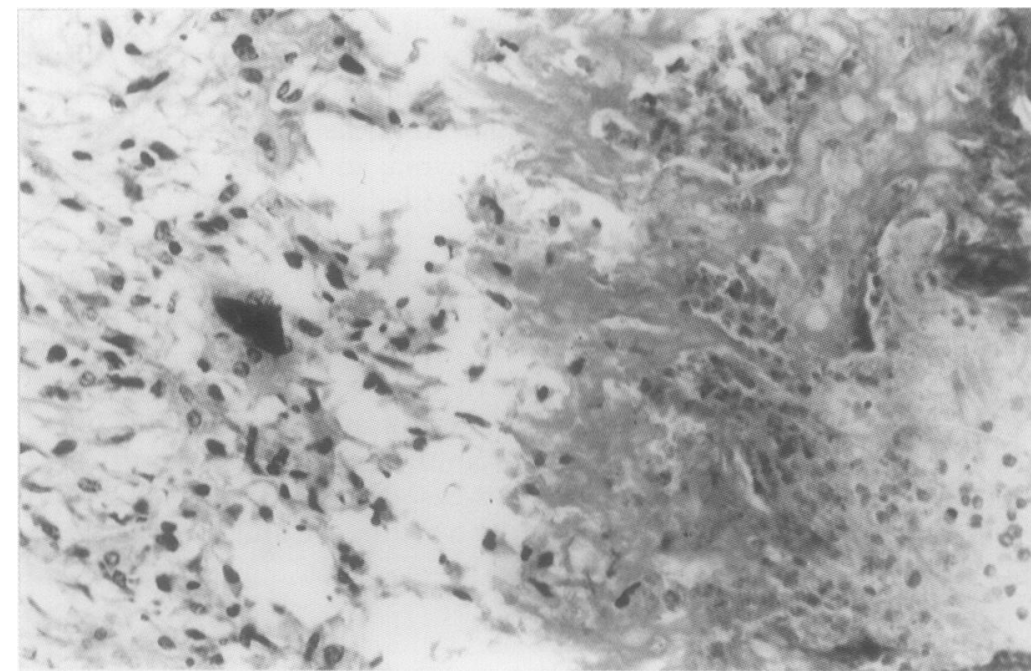

Figure 4 Coagulated amorphous tissue with surrounding histiocytic and giant cell reaction.

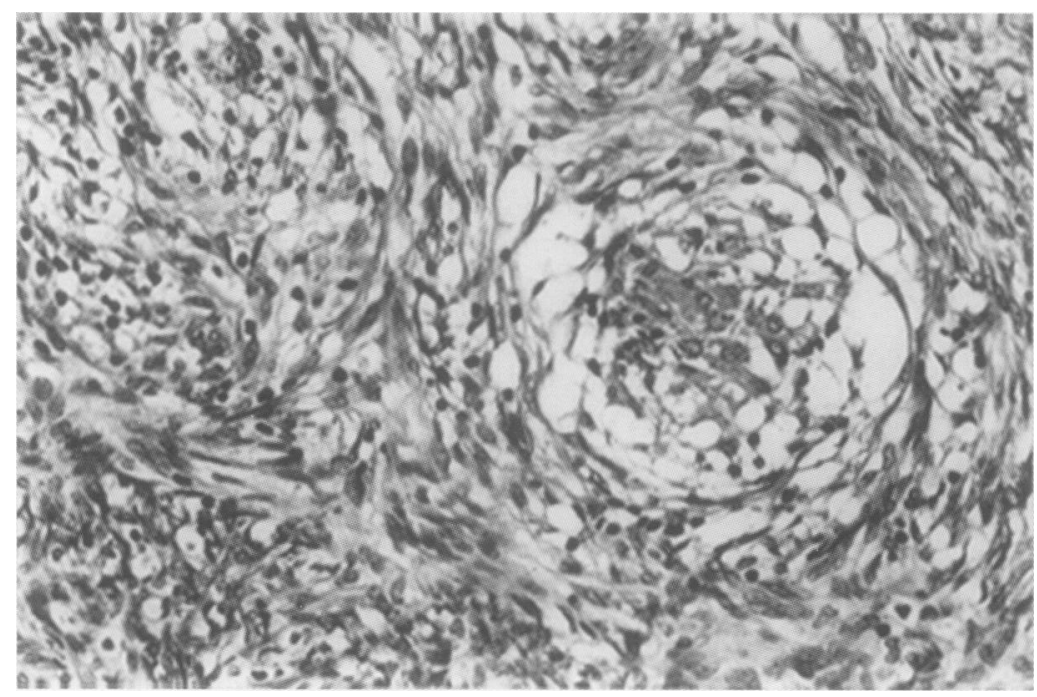

Figure 5 Small, compact idiopathic cortical granuloma of histiocytes and lymphocytes. Collections of lymphocytes are present in the surrounding stroma.

include fungi, actinomyces, schistosomes, and Enterobious vermicularis. A granulomatous reaction may occasionally occur as a non-specific response in a mixed bacterial tubo-ovarian abscess, as in one case in the present study. Demonstration of organisms may require the examination of multiple histological sections with a panel of special stains.

In the present study, the most common cause of ovarian granulomas was a reaction to suture material introduced during a previous operation. With the increasing emphasis on conservative surgery with ovarian preservation-for example, cystectomy and wedge resection, it is expected that such granulomas will be encountered more frequently. Talc and starch granulomas may also occur postoperatively. They are usually typical foreign body type and, in starch granulomas, the pathognomonic Maltese cross pattern can be demonstrated by examination under polarised light.

Postoperative necrobiotic granulomas involving the prostate and bladder have been well documented. Such lesions have occasionally been described within the ovary, ${ }^{12}$ as well as in other parts of the female genital tract. ${ }^{3}{ }^{4} \mathrm{We}$ identified two cases in the present study. These granulomas, consisting of central fibrinoid necrosis surrounded by palisaded histiocytes and giant cells, raise the possibility of rheumatoid disease or tuberculosis. As far as we are aware, such a lesion has not been described in the ovary of a patient with rheumatoid arthritis. Pathologists should be aware that necrotising ovarian granulomas may occur as a reaction to previous surgery. Kernohan $e t a t$ described two cases of non-infectious palisading granuloma of the ovary with central fibrinoid necrosis, similar to postoperative necrotising granulomas. In neither case was there a history of rheumatoid disease or previous ovarian surgery.

The second most common identifiable cause of ovarian granulomas in the present study was Crohn's disease. This suggests that ovarian involvement in Crohn's disease may be more common than is generally realised. One of these cases has been the subject of a previous report ${ }^{6}$ and several other cases of ovarian involvement in Crohn's disease have been documented. ${ }^{7-10}$ Three of the cases we identified showed similar histological features. Fissure ulcers, lined by inflammatory granulation tissue, extended from the ovarian surface deep into the parenchyma. Numerous granulomas were present, many of which contained central areas of suppuration. Occasional fragments of vegetable material were identified which elicited a foreign body giant cell reaction. In these cases, the ovaries were adherent to adjacent segments of bowel and the histological features suggest that the granulomatous involvement was due to direct extension of the inflammatory process from adjacent segments of intestine. This is similar to the pathogenesis of the fistulous tracts between segments of bowel and between cutaneous surfaces and bowel which are commonly seen in Crohn's disease. Right sided ovarian involvement is more common in Crohn's disease resulting from adjacent terminal ileitis. However, the left ovary may be affected by extension from diseased sigmoid colon. The fourth case of ovarian involvement in a patient with Crohn's disease showed a different picture with several small, well circumscribed granulomas near the cortical surface. It may be that these granulomas were not related to the Crohn's disease but were small idiopathic cortical granulomas.

Diathermy granulomas involving the ovary may occur in patients who have had laparoscopic cauterisation for conditions such as endometriosis. ${ }^{11}$ Amorphous coagulated tissue is surrounded by a granulomatous reaction containing foreign body giant cells. Similar lesions have been described in the fallopian tube following tubal diathermy. ${ }^{12}$ In the two cases we describe, laparoscopic cauterisation had been performed 18 and 12 months previously. Pathologists should be aware of this condition as the history of previous ovarian cauterisation may not always be provided.

A histiocytic reaction in the ovary may occur in association with endometriosis. Such reactions are not usually granulomatous but consist of histiocytes which may contain both haemo- 
siderin and lipofuschin pigment. Clement et $a l^{13}$ described cases of ovarian and peritoneal necrotic pseudoxanthomatous nodules in patients with endometriosis. In these cases, foci of recognisable endometriosis were sparse and were only identified by examination of multiple sections. Cases such as these were excluded from our study as were cases of granulomatous reaction to leaked contents of cystic teratomas. However, we identified a single case in which small, well circumscribed ovarian granulomas coexisted with endometriosis. Whether this represents a reaction to the nearby endometriosis is uncertain. Another granuloma-like process which may occasionally affect the ovary is malacoplakia. ${ }^{14}$

There were five cases of ovarian granulomas for which no cause was apparent, even after examination of the case records. All occurred as an incidental finding in an ovary removed during hysterectomy. The histological features in all cases were remarkably similar. Varying numbers of small, compact, well circumscribed and non-necrotising granulomas were confined to the ovarian cortex. The granulomas were composed of lymphocytes, histiocytes, and multinucleate giant cells. In several cases, scattered collections of small lymphocytes were also present within the cortex, perhaps suggesting an early stage in the evolution of ovarian granulomas. Such idiopathic cortical granulomas were first described in postmenopausal ovaries by Hertig in $1944^{15}$ and elaborated upon in a subsequent study. ${ }^{16}$ Similar lesions were described later by Hughesdon. ${ }^{17}$ The authors of these studies considered that they were modified stromal lesions, representing a reaction to regressing hyperplastic stromal nodules and suggested they were confined to postmenopausal ovaries. However, in the present study we identified identical granulomas in the ovaries of premenopausal and perimenopausal women. Herbold et $a l^{18}$ described four apparently idiopathic cases of ovarian granulomas in premenopausal women, none of whom had a history of systemic granulomatous disease. However, in three patients there was a history of previous ovarian surgery and, although organisms were not identified, the histological features in the fourth were suggestive of an infectious process.

The fact that only five cases of idiopathic cortical granulomas were identified is somewhat surprising. Such granulomas are generally accepted to comprise the majority of cases of ovarian granulomas $-40 \%$ of cases in women over age 40 has been quoted in some standard texts. These granulomas are usually few in number and, since only one or two histological sections of a grossly normal ovary will generally be examined, may be missed by standard pathological analysis. In addition, such granulomas may easily be overlooked by the pathologist or not be commented upon in surgical reports. Even if identified they may not be coded, presumably accounting for their sparsity in the present study, which essentially has identified ovarian granulomas that were clinically relevant.

Ovarian involvement has rarely been reported in sarcoidosis ${ }^{19-21}$ and the small idiopathic cortical granulomas described may result from this condition. In all cases, follow up, which ranged from a few months to four years, did not reveal evidence of systemic granulomatous disease. As with apparently isolated granulomatous involvement of other organs, systemic diseases such as sarcoidosis should be excluded before designating such granulomas as idiopathic. However, the histological features are sufficiently distinctive that the term idiopathic cortical granulomas can be confidently applied when such lesions are identified by the surgical pathologist.

We thank Dr R Clarke (Craigavon Area Hospital), Dr D Hughes (Altnagelvin Hospital), and Dr B Kenny (Antrim Area Hospital) for their assistance in collecting material for this paper.

1 Wilson GE, Haboubi NY, McWilliam LJ, Hirsch PJ Postoperative necrotising granulomata in the cervix and ovary. F Clin Pathol 1990;43:1037-8.

2 Dawoud AA, Yates R, Foulis AK. Postoperative necrotising granulomas in the ovary. $\mathcal{F}$ Clin Pathol 1991;44:524-5.

3 Christie AJ, Krieger HA. Indolent necrotising granulomas of the uterine cervix, possibly related to chlamydial of the uterine cervix, possibly related to chla

4 Evans CS, Goldman RL, Klein HZ, Kohbut MD. Necrobiotic granulomas of the uterine cervix. A probable post-operative reaction. Am f Surg Pathol 1984;8:841-4.

5 Kernohan NM, Best PV, Jandial V, Kitchener HC. Palisading granuloma of the ovary. Histopathology 1991;19:27980 .

6 Allen DC, Calvert CH. Crohn's ileitis and salpingooophoritis. Ulster Med f 1995;64:95-7.

7 Wlodarski FM, Trainer TD. Granulomatous oophoritis and salpingitis associated with Crohn's disease of the appendix. Am 7 Obstet Gynecol 1975;122:527-8.

8 Frost SS, Elstein MP, Latour F, Roth JLA. Crohn's disease of the mouth and ovary. Dig Dis Sci 1981;26:568-71.

9 Honore LH. Combined suppurative and non-caseating granulomatous oophoritis associated with distal ileitis (Crohn's disease). Eur $f$ Obstet Gynecol Reprod Biol 1981;12:91-4

10 Goldberg SD, Gray RR, Cadesky KI, Mackenzie RI Oophorovesicular-colonic fistula: a rare complication of Crohn's disease. Can $\mathcal{F}$ Surg 1988;31:427-8.

11 Russell P, Bannatyne P. Non-infectious inflammatory lesions. Surgical pathology of the ovaries. Edinburgh: Churchill Livingstone, 1989:143-57.

12 Roberts JT, Roberts GT, Maudsley RF. Indolent granulomatous necrosis in patients with previous tubal diathermy. Am $\mathcal{F}$ Obstet Gynecol 1977;129:1 12-13.

13 Clement PB, Young RH, Scully RE. Necrotic pseudoxanthomatous nodules of ovary and peritoneum in endomethomatous nodules of ovary and periton
triosis. Am $\mathcal{F}$ Surg Pathol 1988;12:390-7.

14 Klempner LB, Giglio PG, Niebles A. Malacoplakia of the ovary. Obstet Gynecol 1987;69:537-40.

15 Hertig AT. The aging ovary-a preliminary note. $f$ Clin Endocrinol 1944;4:581-2.

16 Woll E, Hertig AT, Smith GVS, Johnson LC. The ovary in endometrial carcinoma. With notes on the morphological history of the aging ovary. Am $\mathcal{F}$ Obstet Gynecol 1948;56: 617-33.

17 Hughesdon PE. The endometrial identity of benign stromatosis of the ovary and its relation to other forms of endometriosis. 7 Pathol 1976;119:201-9.

18 Herbold DR, Frable WJ, Kraus FT. Isolated noninfectious granulomas of the ovary. Int $\mathcal{F}$ Gynecol Pathol 1984;2:380 91.

19 Winslow RC, Funkhouser JW. Sarcoidosis of the female reproductive organs. Obstet Gynecol 1968;32:285-9.

20 Chalvardjian A. Sarcoidosis of the female genital tract. $A m \mathcal{F}$ Obstet Gynecol 1978;132:78-80.

21 White A, Flaris N, Elmer D, Lui R, Fanburg BL Coexistence of mucinous cystadenoma of the ovary and ovarian sarcoidosis. Am f Obstet Gynecol 1990;162:1284-5. 